\title{
ВЗАЄМОВПЛИВ КРУГОВОГО ОТВОРУ І ОТОЧУЮЧИХ ЙОГО ЕЛІПТИЧНИХ ВКЛЮЧЕНЬ ПРИ ПРУЖНОМУ ДЕФОРМУВАННІ ПРЯМОКУТНОї ПЛАСТИНИ
}

Досліджено напружено-деформований стан прямокутної пружної пластини 3 одним круговим отвором, оточеним двома або чотирма еліптичними включеннями. Визначено вплив відстані між отвором і включеннями, способу їх розташування та механічних властивостей на напружено-деформований стан пластини В місцях локальних концентраторів напружень на основі скінченно-елементного аналізу.

Ключові слова: прямокутна пружна пластина, круговий отвір, еліптичні включення, коефіцієнт концентрації напружень, метод скінченних елементів.

Вступ. Тонкостінні конструкції, елементами яких $є$ пластини і оболонки, знайшли широке застосування в різних галузях техніки - авіації, будівництві, судно- та машинобудуванні, нафтовій промисловості та ін. Порушення суцільності (отвори, пори, тріщини) і наявність у матеріалі різноманітних включень $[1,10] €$ чинником, що зумовлює неоднорідність структури та має суттєвий вплив на концентрацію напружень і процеси деформування та руйнування твердих тіл.

Методи розрахунку пластинчато-оболонкових конструкцій з отворами за різних зовнішніх навантажень розглянуто в багатьох публікаціях. Виділимо з них такі [3-9, 11-13].

У даній роботі досліджено напружено-деформований стан (НДС) прямокутної пластини з одним круговим отвором, оточеним двома або чотирма еліптичними включеннями з іншого матеріалу. Проведено скінченно-елементний аналіз впливу відстані між отвором та включеннями, їх кількості, способу розташування та механічних властивостей на НДС пластини в місцях локальних концентраторів напружень.

Постановка задачі. Дана пружна однорідна ізотропна прямокутна пластина розмірами $l_{1} \times l_{2} 3$ круговим отвором радіусу $r$ i двома (чотирма) однаковими еліптичними включеннями $(a, b$ - більша і менша піввісі еліпсу відповідно), розташованими симетрично відносно отвору на відстані $l$ між їх центрами (рис. 1).

Пластина знаходиться під дією одновісного рівномірного навантаження розтягу ( $p=$ const), що не призводить до появи пластичних деформацій.

Необхідно визначити НДС даної пластини для кожного варіанту розташування включень відносно отвору, вплив відстані між отвором та включеннями та їх механічних властивостей на НДС пластини за заданих граничних умов.

๔ Е. Л. Гарт, Я. В. Рибалко, 2019 


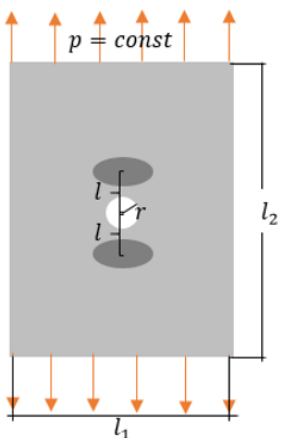

a)

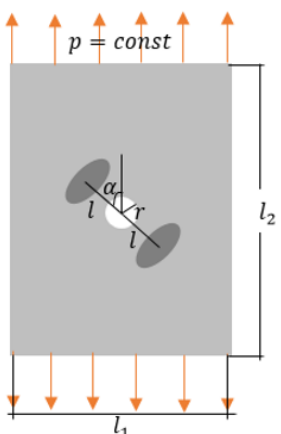

б)

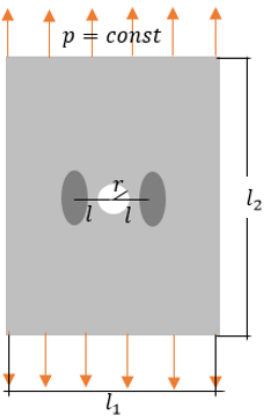

B)

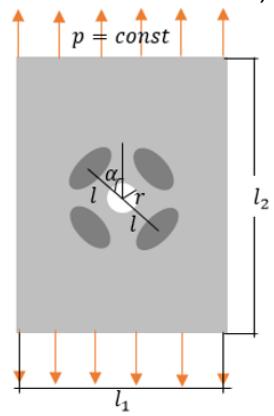

г)

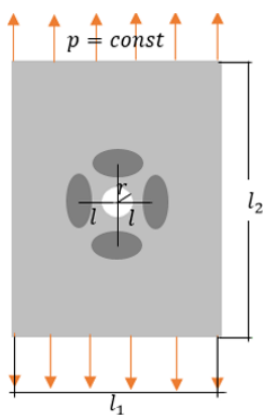

д)

Рис. 1 - Прямокутна пластина 3 одним круговим отвором та еліптичними включеннями: а) вертикальне розташування включень; б) розташування включень під кутом $45^{\circ}$; в) горизонтальне розташування включень;

г) симетричне розташування чотирьох включень під кутом $45^{\circ}$;

д) симетричне розташування чотирьох включень відносно осей Ох і Оу

Математична модель задачі. У варіаційній постановці вихідна задача призводить до мінімізації функціоналу повної потенціальної енергії деформації системи [2]:

$$
\begin{aligned}
I[u, v]=\int_{\Omega_{1}}\left\{2 \mu_{1}\right. & {\left.\left[\left(\frac{\partial u}{\partial x}\right)^{2}+\left(\frac{\partial v}{\partial y}\right)^{2}\right]+\lambda_{1}\left(\frac{\partial u}{\partial x}+\frac{\partial v}{\partial y}\right)^{2}+\mu_{1}\left(\frac{\partial u}{\partial y}+\frac{\partial v}{\partial x}\right)^{2}\right\} d x d y+} \\
& +\sum_{i=2}^{n+1} \int_{\Omega_{\mathrm{i}}}\left\{2 \mu_{i}\left[\left(\frac{\partial u}{\partial x}\right)^{2}+\left(\frac{\partial v}{\partial y}\right)^{2}\right]+\lambda_{i}\left(\frac{\partial u}{\partial x}+\frac{\partial v}{\partial y}\right)^{2}\right. \\
& \left.+\mu_{i}\left(\frac{\partial u}{\partial y}+\frac{\partial v}{\partial x}\right)^{2}\right\} d x d y-\int_{\gamma}\left(P_{x} u+P_{y} v\right) d \gamma
\end{aligned}
$$

де $u(x, y), v(x, y)$ - проекції вектора переміщень на осі $O x$ і $O y$ відповідно; $\lambda_{1}, \mu_{1}-$ константи Ляме матеріалу пластини $\Omega_{1}$ (матриці); $\lambda_{i}, \mu_{i}-$ константи Ляме матеріалу $(i-1)$-го включення $\Omega_{\mathrm{i}}(i=\overline{2, n+1}, n-$ кількість 
включень); $\Omega=\bigcup_{\mathrm{i}=1}^{\mathrm{n}+1} \Omega_{\mathrm{i}}$ - область визначення змінних $x$ та $y ; \gamma$ - границя області $\Omega$, вздовж якої прикладене зовнішнє навантаження інтенсивності $P(x, y)=\left(P_{x}(x, y), P_{y}(x, y)\right)^{T}$.

Метод розв'язування. Для розв'язування отриманої варіаційної задачі застосовано MCE [14], основна ідея якого полягає у дискретизації заданої області неперервної зміни аргументів шуканої функції сукупністю скінченних елементів (скінченною кількістю підобластей) і апроксимації цієї неперервної фрункції в межах кожного скінченного елемента поліномом деякого степеня. Це призводить до заміни вихідної варіаційної задачі дискретною моделлю - системою лінійних або нелінійних алгебричних рівнянь з невідомими значеннями шуканої функції у вузлах скінченно-елементної сітки.

Розрахунки здійсненні при застосуванні трикутних шестивузлових лагранжевих скінченних елементів другого степеня, при цьому невідомі функції переміщень усередині кожного скінченного елемента апроксимовані квадратичним поліномом. У зонах локальної концентрації напружень (навколо отвору), а також на межі включення і пластини (матриці) застосовано спеціальним чином підібрану адаптивну сітку.

Числовий аналіз. Розрахунки проведені на ПК Lenovo Y510P Notebook PC, GeForce GT 755M з тактовою частотою $2,4 \mathrm{GHz}$, оперативною пам'яттю $8 \mathrm{~GB}$, розрядність системи - х64. Кількість скінченних елементів - 6819, кількість вузлів - 13891. Час розрахунків у середньому - 0,2 хв.

Для досліджень використовували пластину розмірами 0,6 $\mu \times 0,8$, з отвором радіусу $r=0,02$ м та двома еліптичними включеннями з півосями $a=0,04 \mu, b=0,02$ м. Матеріали для досліджень брались такі: алюміній $\left(E_{1}=70\right.$ ГПа, $\left.v=0,3, \quad \sigma_{0,2}=415 M \Pi a, \sigma_{\mathrm{B}}=470 \mathrm{M \Pi a}\right), \quad$ сталь $\left(E_{2}=210\right.$ ГПа, $\left.v=0,33, \sigma_{0,2}=620 M \Pi a, \sigma_{\mathrm{B}}=720 M \Pi a\right)$. Навантаження $p=50$ МПа. Обрані матеріали носять умовний характер. При комп'ютерному моделюванні вважалось, що між матрицею і включенням задані умови жорсткого зчеплення.

Введемо коефіцієнт відносної жорсткості включення як відношення його модуля пружності до модуля пружності пластини (матриці): $k=E_{\text {вкл }} / E_{n л}$. Розглянемо випадки, коли $k>1$ (більш «жорстке» включення) і $k<1$ (більш «м'яке» включення).

Аналіз впливу способу розташування включень відносно отвору i впливу відстані між отвором та включеннями (рис. 1, a-d) проведено на основі побудованих графіків розподілу величини відносної інтенсивності напружень $\sigma_{i} / p$ по розгортці отвору пластини.

На рис. 2 і рис. 3 наведено розподіл $\sigma_{i} / p$ вздовж розгортки отвору для випадку вертикального розташування еліптичних включень (рис. 1, а) для різних значень відстані $I(I=8 r, 5 r, 3 r, 2,5 r)$ при $k>1$ і $k<1$ відповідно. 
Зі зближенням «жорстких» включень з отвором значення $\sigma_{i} / p$ в місцях локальної концентрації збільшується (рис. 2) (ККН зростає на 7\%), а для «м'яких» включень, навпаки, зменшується (рис. 3) (ККН зменшується у середньому на 15\%), що пов'язано з перерозподілом напружень при суттєво неоднорідному напружено-деформованому стані.

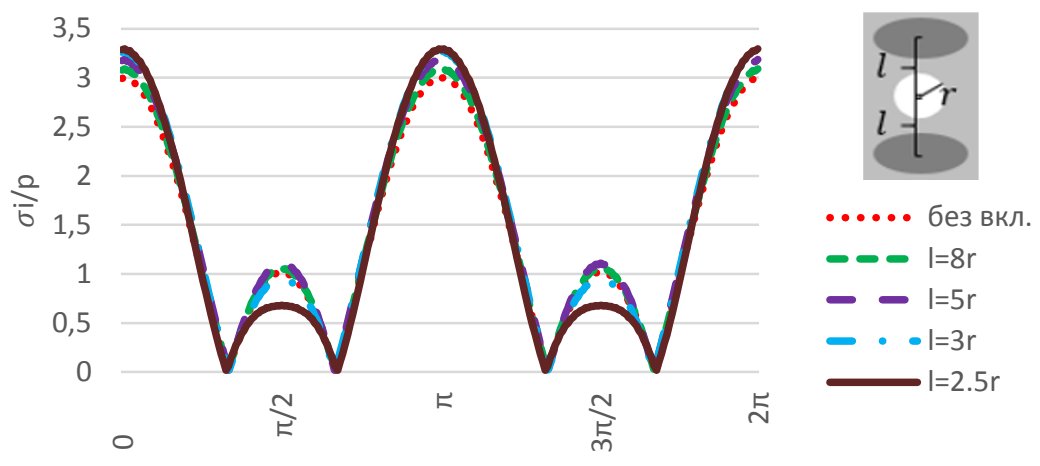

Рис. 2 - Розподіл відносної інтенсивності напружень $\sigma_{i} / p$ по розгортці отвору пластини при $k>1$ для випадку рис. 1 , a

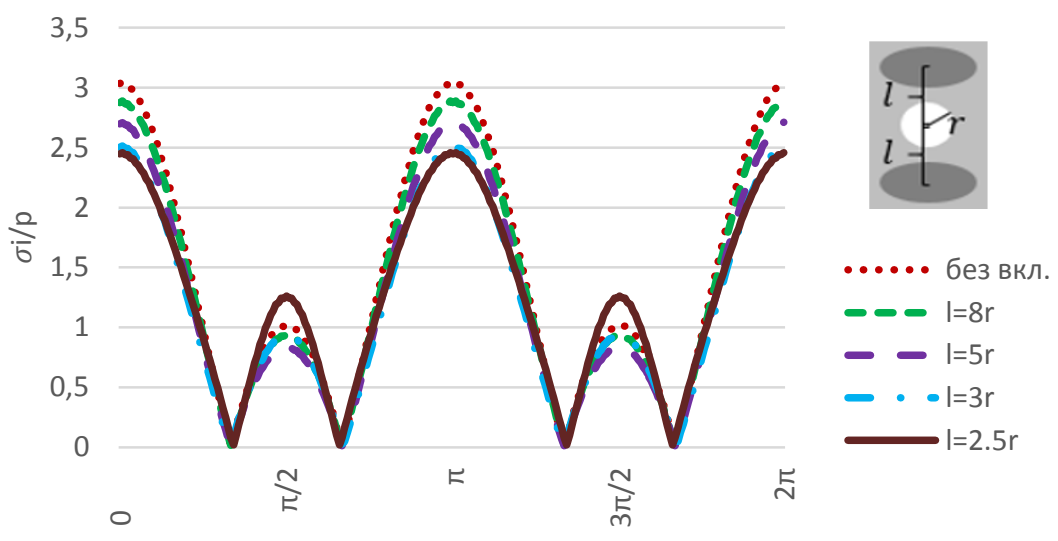

Рис. 3 - Розподіл відносної інтенсивності напружень $\sigma_{i} / p$ по розгортці отвору пластини при $k<1$ для випадку рис. $1, a$

На рис. 4 і рис. 5 наведено розподіл $\sigma_{i} / p$ по розгортці отвору пластини для випадку розташування еліптичних включень під кутом $45^{\circ}$ до осей $O x$ і $O y$ (рис. 1, б) для різних значень відстані $I(I=8 r ; 5 r ; 3 r ; 2,5 r)$ при $k>1$ і $k<1$ відповідно. 


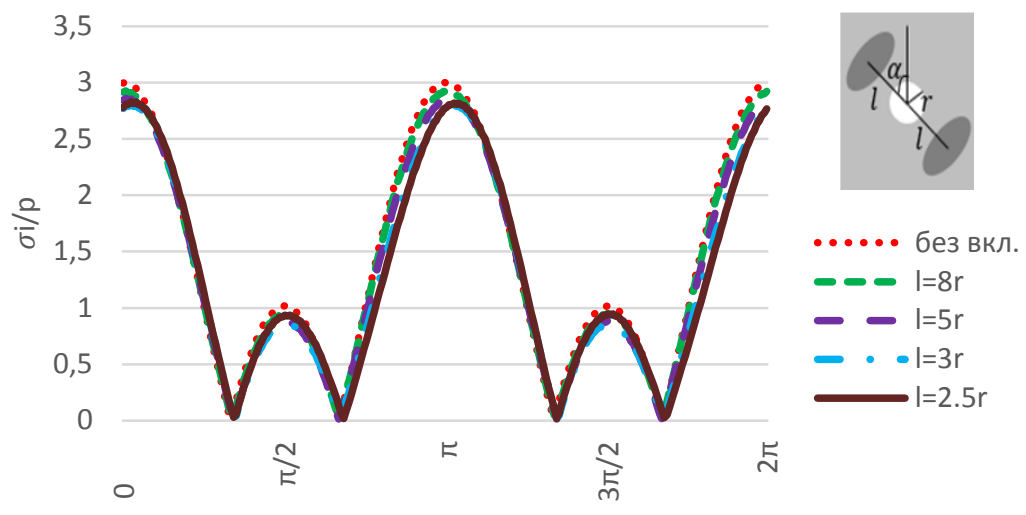

Рис. 4 - Розподіл відносної інтенсивності напружень $\sigma_{i} / p$ по розгортці отвору пластини при $k>1$ для випадку рис. 1,6

3 рис. 4 видно, що зі зближенням з отвором «жорстких» включень, розташованих під кутом $45^{\circ}$ до координатних осей $O x$ і $O y$, відносна інтенсивність напружень в місцях локальної концентрації зменшується (ККН зменшується у середньому на 7\%). При цьому спостерігається механічний ефект: відбувається зміна локації зон концентрації напружень (зміщення в напрямку за годинниковою стрілкою). Тобто асиметричне розташування «жорстких» включень впливає на перерозподіл напружень в околі отвору таким чином, що має місце своєрідний зсув зони максимальних напружень навколо локальних концентраторів в напрямку, протилежному розташуванню включень. В залежності від відстані між отвором і включеннями величина зсуву змінюється - зростає при наближенні до отвору у порівнянні з випадком для пластини без включень.

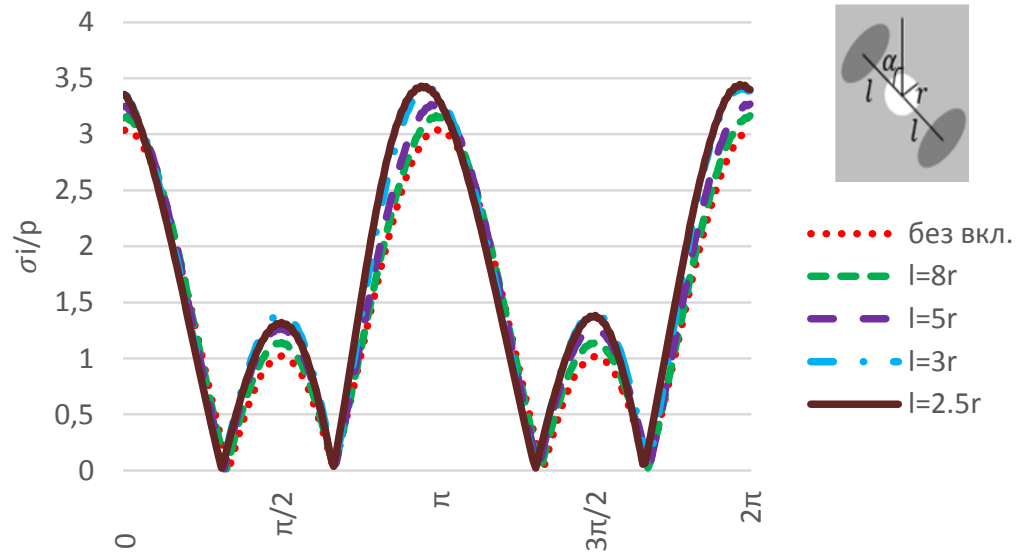

Рис. 5 - Розподіл відносної інтенсивності напружень $\sigma_{i} / p$ по розгортці отвору пластини при $k<1$ для випадку рис. 1, 6 
На відміну від розглянутого випадку зближення з отвором «м'яких» включень, розташованих під кутом $45^{\circ}$ до координатних осей $O x$ і $O y$ (рис. 5), призводить до збільшення відносної інтенсивності напружень в місцях локальної концентрації (ККН збільшується на 7\%). При цьому також спостерігається механічний ефрект: відбувається зміна локації зон концентрації напружень (зміщення в напрямку проти годинникової стрілки). Тобто асиметричне положення «м'яких» включень впливає на перерозподіл напружень в околі отвору таким чином, що має місце зсув зони максимальних напружень навколо локальних концентраторів.

На рис. 6 і рис. 7 наведено розподіл $\sigma_{i} / p$ вздовж розгортки отвору пластини для випадку горизонтального розташування еліптичних включень (рис. 1, в) для різних значень відстані $I(I=8 r, 5 r, 3 r, 2,5 r)$ при $k>1$ i $k<1$ відповідно.

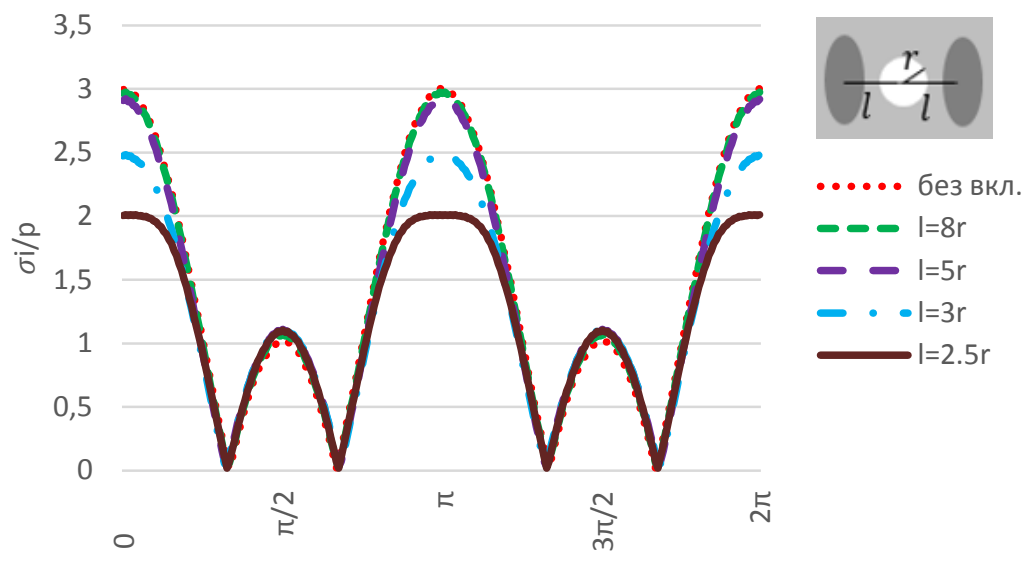

Рис. 6 - Розподіл відносної інтенсивності напружень $\sigma_{i} / p$ по розгортці отвору пластини при $k>1$ для випадку рис. $1, \boldsymbol{\theta}$

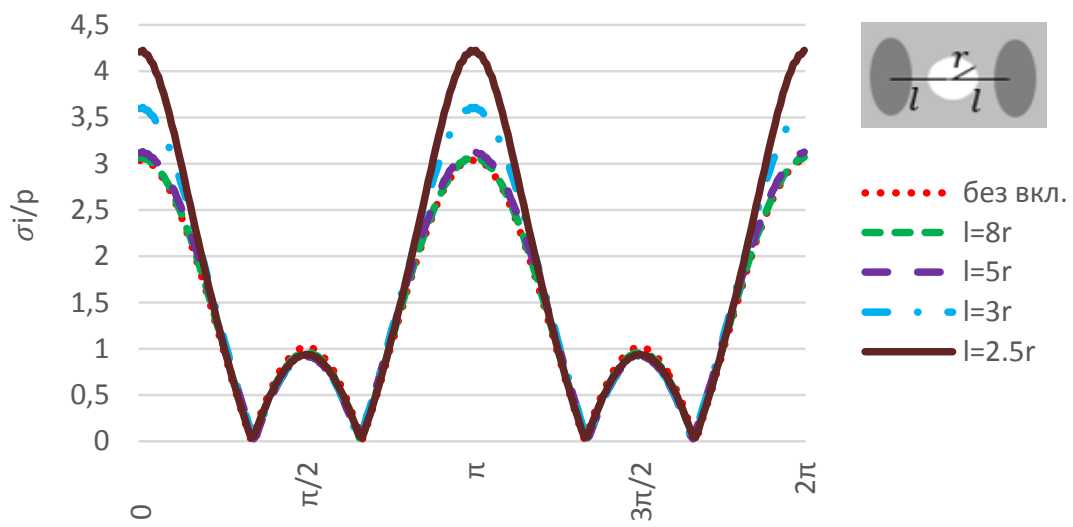

Рис. 7 - Розподіл відносної інтенсивності напружень $\sigma_{i} / p$ по розгортці отвору пластини при $k<1$ для випадку рис. 1,6 
Так, зближення «жорстких» включень з отвором (рис. 6) призводить до зменшення максимальних значень відносної інтенсивності напружень (ККН зменшується у середньому на 15\%), що пов'язано з перерозподілом напружень в зонах локальних концентраторів за рахунок підкріплення небезпечних областей більш жорстким матеріалом. При цьому значення ККН можна зменшити при певній відстані майже на 33\%. Для «м'яких» включень (рис. 7) спостерігається протилежна картина: ККН, навпаки, збільшується у середньому на 15\% у зв'язку з послабленням небезпечної зони навколо отвору в наслідок появи в неї більш м'якого матеріалу.

На рис. 8 і рис. 9 подано розподіл $\sigma_{i} / p$ вздовж розгортки отвору пластини для випадку чотирьох еліптичних включень, симетрично розташованих під кутом $45^{\circ}$ до координатних осей $O x$ і $O y$ (рис. 1, 2) для різних значень відстані $/(l=8 r, 5 r, 3 r, 2,5 r)$ при $k>1$ і $k<1$ відповідно.

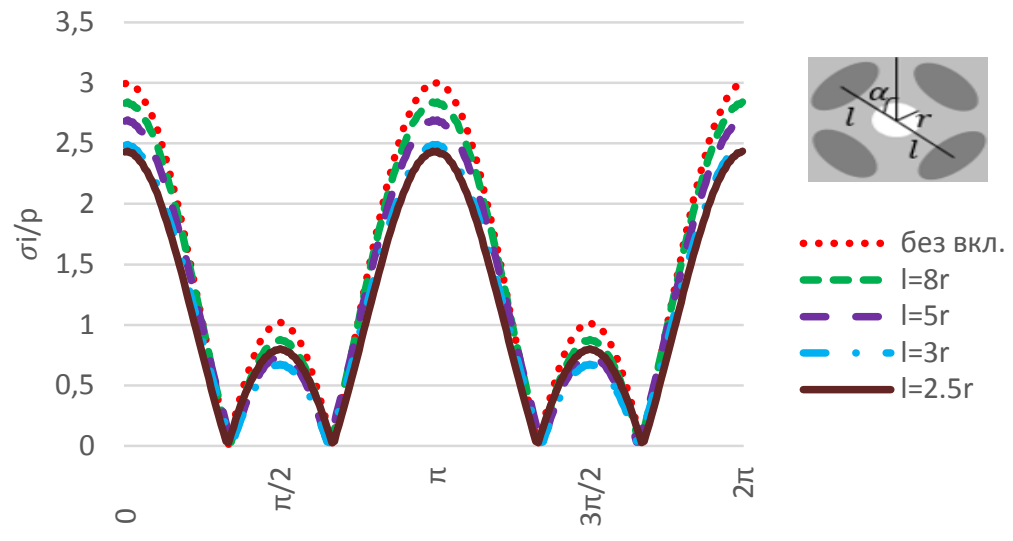

Рис. 8 - Розподіл відносної інтенсивності напружень $\sigma_{i} / p$ по розгортці отвору пластини при $k>1$ для випадку рис. 1 , 2

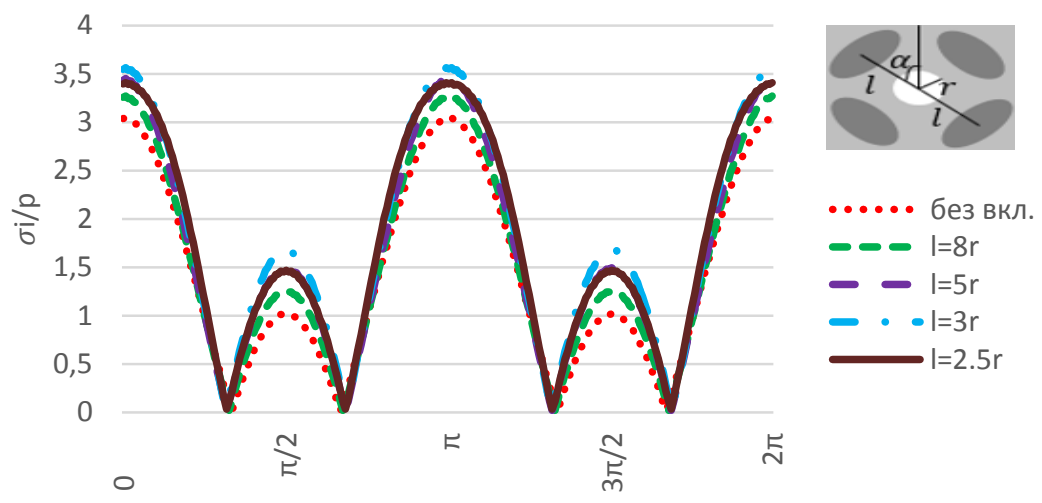

Рис. 9 - Розподіл відносної інтенсивності напружень $\sigma_{i} / p$ по розгортці отвору пластини при $k<1$ для випадку рис. 1 , 2 
Зі зближенням «жорстких» включень з отвором (рис. 8) відносна інтенсивність напружень зменшується (ККН зменшується у середньому на 13\%). При цьому симетричне розташування включень не призводить до зміни положення небезпечних зон навколо локальних концентраторів напружень. У порівнянні з випадком рис. 1, б значення ККН при цьому зменшується майже у 2 рази. Для «м'яких» включень, навпаки, зближення з отвором призводить до збільшення ККН у середньому на 13\%).

На рис. 10 і рис. 11 наведено розподіл $\sigma_{i} / p$ по розгортці отвору пластини для випадку чотирьох еліптичних включень, симетрично розташованих відносно осей $O x$ і $O y$ (рис. $1, \partial)$ для різних значень відстані $I(l=8 r$, $5 r, 3 r, 2,5 r)$ при $k>1$ і $k<1$ відповідно.

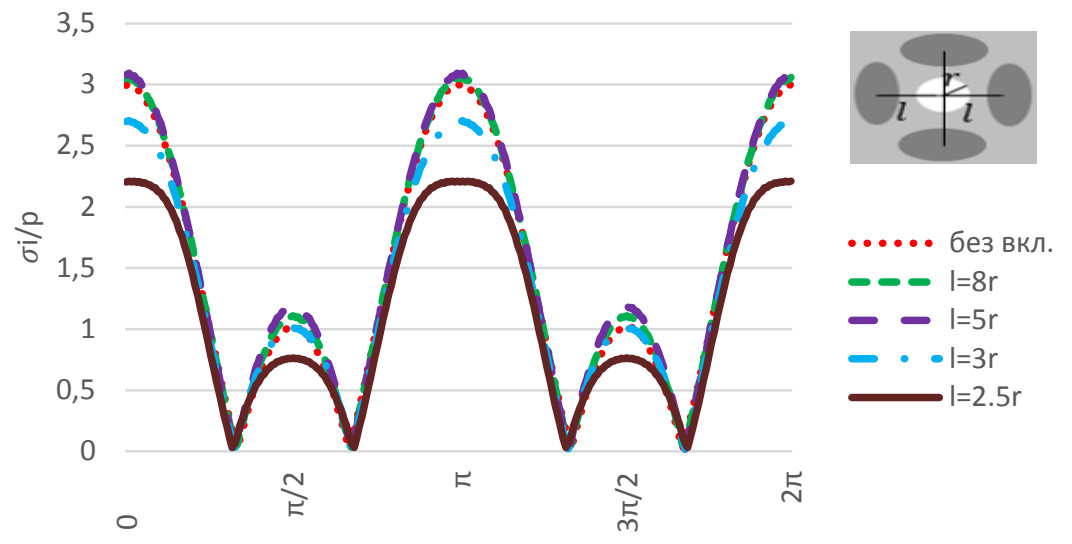

Рис. 10 - Розподіл відносної інтенсивності напружень $\sigma_{i} / p$ по розгортці отвору пластини при $k>1$ для випадку рис. $1, \partial$

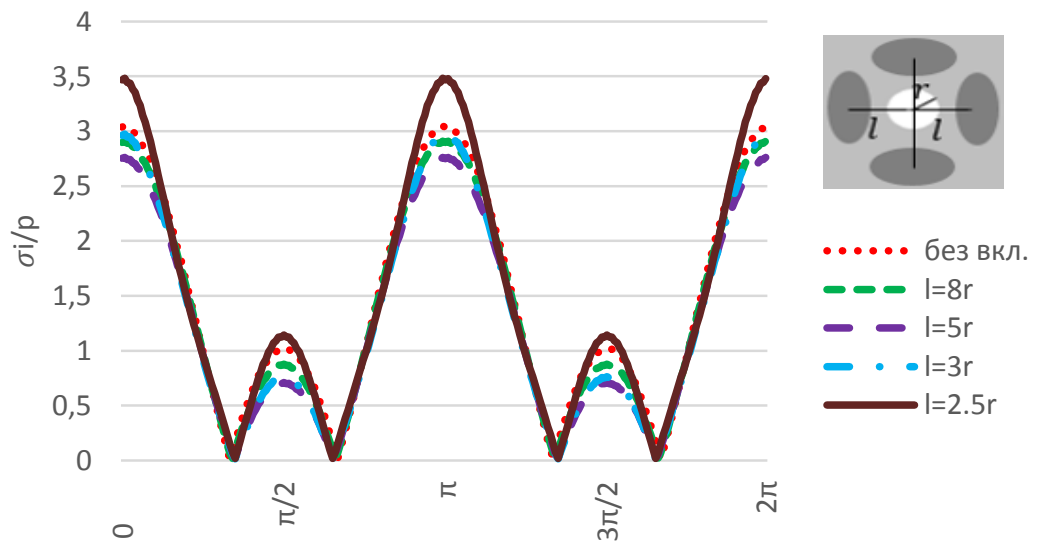

Рис. 11 - Розподіл відносної інтенсивності напружень $\sigma_{i} / p$ по розгортці отвору пластини при $k<1$ для випадку рис. $1, \partial$ 
Зближення «жорстких» включень з отвором (рис. 10) призводить до зменшення відносної інтенсивності напружень при певних відстанях $(I=3 r, 2,5 r)$, при цьому ККН зменшується у середньому на $18 \%$. У разі $I=8 r$ та $I=5 r$ ККН незначно зростає (на $2-3 \%$ ) по відношенню з випадком пластини без включень. Це має місце також і для вертикального розташування "жорстких» включень (рис. 1, а), при якому спостерігається зростання ККН на 3-6\%. Зближення більш «жорстких» включень з отвором призводить до перерозподілу напружень навколо нього і своєрідного його підкріплення. Для «м'яких» включень маємо іншу картину розподілу напружень: зі зближенням їх з отвором для відстаней $I=8 r$; $5 r$, 3r відносна інтенсивність напружень зменшується, при цьому ККН зменшується у середньому на $4 \%$, але при подальшому зменшенні відстані до $I=2,5 r$ KКН збільшується майже на 16\%. Зі зближенням 3 отвором «м'яких» по відношенню до матеріалу пластини включень міцність небезпечних зон зменшується, що призводить до зростання ККН.

У табл. 1 наведено значення ККН для розглянутих п'яти випадків розташування еліптичних включень (рис. $1, a-\partial$ ) для різних варіантів відстані $(l=8 r, 5 r, 3 r, 2,5 r)$ між отвором та «жорстким» $(\mathrm{k}>1)$ або «м'яким» $(\mathrm{k}<1)$ включенням.

Таблиця 1 - Значення ККН для випадків, зображених на рис. 1, a - $\partial$

\begin{tabular}{|c|c|c|c|c|c|c|c|c|c|c|}
\hline \multirow{2}{*}{ Задача } & \multicolumn{2}{|c|}{$\begin{array}{c}\text { Вертикальні } \\
\text { включення }\end{array}$} & \multicolumn{2}{|c|}{$\begin{array}{l}\text { Включення під } \\
\text { кутом } 45^{\circ} \text { до } \\
\text { осей Ох і Оу }\end{array}$} & \multicolumn{2}{|c|}{$\begin{array}{c}\text { Горизонтальні } \\
\text { включення }\end{array}$} & \multicolumn{2}{|c|}{\begin{tabular}{|c|} 
Чотири \\
включення \\
під кутом $45^{\circ}$ \\
до осей Ох і Oy
\end{tabular}} & \multicolumn{2}{|c|}{$\begin{array}{c}\text { Чотири } \\
\text { включення, } \\
\text { симетричні } \\
\text { відносно осей } \\
\text { Ох і Оy }\end{array}$} \\
\hline & $k>1$ & $k<1$ & $k>1$ & $k<1$ & $k>1$ & $k<1$ & $k>1$ & $k<1$ & $k>1$ & $k<1$ \\
\hline$l=8 r$ & 3,09 & 2,89 & 2,92 & 3,16 & 2,98 & 3,07 & 2,82 & 3,25 & 3,06 & 2,91 \\
\hline$l=5 r$ & 3,19 & 2,71 & 2,86 & 3,25 & 2,92 & 3,13 & 2,67 & 3,43 & 3,09 & 2,76 \\
\hline$I=3 r$ & 3,27 & 2,51 & 2,79 & 3,34 & 2,48 & 3,61 & 2,49 & 3,54 & 2,71 & 2,97 \\
\hline$l=2,5 r$ & 3,29 & 2,46 & 2,81 & 3,34 & 2,01 & 4,22 & 2,41 & 3,39 & 2,21 & 3,48 \\
\hline
\end{tabular}

У табл. 2 подано зміни ККН у відсотковому відношенні для всіх розглянутих випадків (рис. 1, a-d) у порівнянні з результатами для пластини з круговим отвором без включень.

Таким чином, встановлено:

1. У випадку вертикального розташування включень (рис. 1, а): при k>1 зі зменшенням відстані / між включеннями та отвором спостерігається збільшення ККН, при цьому при найменшій із розглянутих відстаней цей показник збільшився до $10 \%$; при $\mathrm{k}<1$ зі зменшенням відстані I величина ККН зменшилась, а при найменшій із розглянутих відстаней цей показник зменшився до $19 \%$.

2. У випадку розташування включень під кутом $45^{\circ}$ до осей $O x$ і $O y$ (рис. 1, б): при k>1 зі зменшенням відстані / величина ККН зменшувалась, при цьому виявлено новий механічний ефект: розташування зон 
локальної концентрації змінилось (відбувся їх зсув у певному напрямку), а при найменшій із розглянутих відстаней / значення ККН зменшилось на $8 \%$; при $\mathrm{k}<1$ спостерігається збільшення ККН і також механічний ефект: зміна локації зон локальної концентрації напружень у певному напрямку, при цьому при найменшій із розглянутих відстаней значення ККН збільшилось на $~ 11 \%$.

3. У випадку горизонтального розташування включень (рис. 1, в): при k>1 зі зменшенням відстані / величина ККН зменшувалась, а при найменшій із розглянутих відстаней / значення ККН зменшилось на $\sim 33 \%$; при $\mathrm{k}<1$ спостерігається збільшення ККН, при цьому при найменшій із розглянутих відстаней значення ККН збільшилось на $39 \%$.

4. У випадку симетричного розташування чотирьох включень під кутом $45^{\circ}$ до осей $O x$ і $O y$ (рис. 1, 2): при k>1 зі зменшенням відстані / величина ККН зменшувалась, а при найменшій із розглянутих відстаней / значення ККН зменшилось на 19\%; при k<1 спостерігається збільшення ККН, при цьому при найменшій відстані значення ККН збільшилось на 13\%.

5. У випадку симетричного розташування чотирьох включень відносно осей $O x$ і $O y$ (суперпозиція випадків рис. 1 , а та рис. 1, в) (рис. 1, )): при k>1 зі зменшенням відстані / до значення $5 r$ величина ККН збільшилась до $\sim 3 \%$, але далі з наближенням включень до отвору значення ККН зменшилось на $\sim 26 \%$; при $\mathrm{k}<1$ спостерігається незначне зменшення ККН до $\sim 8 \%$ при $l=3 r$, але при $l=2,5$ г значення ККН збільшилось на $\sim 16 \%$.

Таблиця 2 - Відхилення ККН (\%) для випадків, зображених на рис. 1, а-д, від значення ККН для пластини 3 отвором без включень

\begin{tabular}{|c|c|c|c|c|c|c|c|c|c|c|}
\hline \multirow{2}{*}{ Задача } & \multicolumn{2}{|c|}{$\begin{array}{c}\text { Вертикальні } \\
\text { включення }\end{array}$} & \multicolumn{2}{|c|}{$\begin{array}{l}\text { Включення під } \\
\text { кутом } 45^{\circ} \text { до } \\
\text { осей Оx і Оу }\end{array}$} & \multicolumn{2}{|c|}{$\begin{array}{c}\text { Горизонтальні } \\
\text { включення }\end{array}$} & \multicolumn{2}{|c|}{\begin{tabular}{|c|} 
Чотири \\
включення \\
під кутом $45^{\circ}$ \\
до осей Ox і Oy
\end{tabular}} & \multicolumn{2}{|c|}{\begin{tabular}{|c|} 
Чотири \\
включення, \\
симетричні \\
відносно осей \\
Ох і Оу \\
\end{tabular}} \\
\hline & $k>1$ & $k<1$ & $k>1$ & $k<1$ & $k>1$ & $k<1$ & $k>1$ & $k<1$ & $k>1$ & $k<1$ \\
\hline$I=8 r$ & $+3 \%$ & $-5 \%$ & $-3 \%$ & $+4 \%$ & $-1 \%$ & $+1 \%$ & $-6 \%$ & $+8 \%$ & $+2 \%$ & $-3 \%$ \\
\hline$I=5 r$ & $+6 \%$ & $-11 \%$ & $-5 \%$ & $+7 \%$ & $-3 \%$ & $+3 \%$ & $-11 \%$ & $+14 \%$ & $+3 \%$ & $-8 \%$ \\
\hline$I=3 r$ & $+9 \%$ & $-17 \%$ & $-7 \%$ & $+11 \%$ & $-17 \%$ & $+18 \%$ & $-17 \%$ & $+18 \%$ & $-10 \%$ & $-1 \%$ \\
\hline$I=2,5 r$ & $+10 \%$ & $-19 \%$ & $-8 \%$ & $+11 \%$ & $-33 \%$ & $+39 \%$ & $-19 \%$ & $+13 \%$ & $-26 \%$ & $+16 \%$ \\
\hline
\end{tabular}

Висновки. Результати проведених числових досліджень та їх аналіз дають змогу зробити висновок про суттєвий вплив відстані між включеннями та отвором, їх кількості, взаємного розташування і механічних властивостей матеріалу включень на НДС пластини в околі локальних концентраторів напружень.

Отже, із розглянутих варіантів розташування еліптичних включень навколо кругового отвору найкращим з точки зору зменшення концентрації напружень виявився варіант їх горизонтального розташування (рис. 1, в) у разі використання більш «жорстких» включень $(\mathrm{k}>1)$, що дало змогу 
зменшити значення ККН на $~ 33 \%$. У разі більш «м'яких» включень $(k<1)$ найкращим виявився випадок їх вертикального розташування (рис. 1, a), при цьому значення ККН можливо зменшити на 19\%.

Виявлений новий механічний ефект, пов'язаний з впливом певного розташування еліптичних включень («жорстких» або «м'яких») навколо кругового отвору на зміщення (зсув) областей максимальних напружень у заданому напрямку. Це відкриває можливість керувати локацією зон концентрації напружень навколо отвору за рахунок певного розташування включень.

\section{БІБЛІОГРАФІЧНІ ПОСИЛАННЯ}

1. Ванин Г. А. Микромеханика композиционных материалов. К.: Наукова думка, 1985. 302 c.

2. Васидзу К. Вариационные методы в теории упругости и пластичности. М.: Мир, 1987. 544 с.

3. Гарт Э. Л. Конечноэлементный анализ плоскодеформируемых сред с включениями // Вісник Дніпропетр. ун-ту. Сер.: Механіка. 2011. Вип. 15, т. 2. С. 39-47.

4. Гарт Э. Л., Панченко С. В. Численный анализ напряжённо-деформированного состояния пластины с прямоугольным отверстием, подкреплённым треугольными накладками // Проблеми обчислювальної механіки і міцності конструкцій: зб. наук. праць. - Дніпропетровськ: Ліра, 2015. Вип. 24. С. 35-47.

5. Гарт Е. Л., Ніжніченко К. О. Числовий аналіз рівноваги пружної пластини 3 включенням на основі проекційно-ітераційного варіанта методу скінченних елементів // Техническая механика. 2011. № 1. С. 61-69.

6. Гарт E. Л., Гудрамович В. С. Проекційно-ітераційні схеми реалізації методу скінченних елементів в задачах деформування пластин з отворами та включеннями // Матем. методи і фріз.-мех. поля. 2013. Т. 56, № 2. С. 48-59.

7. Гарт Е. Л., Різник В. О. Комп'ютерне моделювання поведінки пластини з двома ромбовидними отворами // Проблеми обчислювальної механіки і міцності конструкцій: зб. наук. праць. - Дніпро: Ліра, 2017. Вип. 27. С. 43-51.

8. Гудрамович В. С., Гарт Э. Л., Струнин К. А. Компьютерное моделирование поведения упругой среды с двумя сопряженными эллипсообразными включениями // Проблеми обчислювальної механіки і міцності конструкцій: зб. наук. праць. - Дніпро: Ліра, 2017. Вип. 26. С. 42-50.

9. Савин Г. Н. Распределение напряжений около отверстий. К.: Наукова думка, 1968. $888 \mathrm{c}$.

10. Штерн М. Б., Рудь В. Д. Механічні та комп'ютерні моделі консолідації гранульованих середовищ на основі порошків металів і кераміки при деформуванні та спіканні / під ред. В. В. Скорохода. Луцьк: Луцьк. нац. техн. ун-т, 2010. 232 с.

11. Gudramovich V. S., Gart É. L., Strunin K. A. Modeling of the behavior of planedeformable elastic media with elongated elliptic and rectangular inclusions // Materials Science. 2017. Vol. 52, Iss. 6. P. 768-774.

12. Hart E. L., Hudramovich V. S. Projection-iterative schemes for the realization of the finite-element method in problems of deformation of plates with holes and inclusions // Journal of Mathematical Sciences. 2014. Vol. 203. No. 1. P. 55-69.

13. Hart E. L., Hudramovich V. S. Projection-iterative modification of the method of local variations for problems with a quadratic functional // J. Appl. Math. Mech. 2016. Vol. 80, Iss. 2. P. 156-163.

14. Zienkiewicz O. C., Teylor R. L. The finite element method for solid and structural mechanics. New York: Elsevier, 2005. 632 p. 


\title{
Э. Л. Гарт, д-р физ.-мат. наук, Я. В. Рыбалко \\ ВЗАИМОВЛИЯНИЕ КРУГОВОГО ОТВЕРСТИЯ И ОКРУЖАЮЩИХ ЕГО ЭЛЛИПТИЧЕСКИХ ВКЛЮЧЕНИЙ ПРИ УПРУГОМ ДЕФОРМИРОВАНИИ ПРЯМОУГОЛЬНОЙ ПЛАСТИНЫ
}

Исследовано напряженно-деформированное состояние прямоугольной упругой пластины с одним круговым отверстием, окруженным двумя или четырьмя эллиптическими включениями. Изучено влияние расстояния между отверстием и включениями, способа их расположения и механических свойств на напряженно-деформированное состояние пластины в местах локальных концентраторов напряжений на основе конечноэлементного анализа.

Ключевые слова: прямоугольная упругая пластина, круговое отверстие, эллиптические включения, коэффициент концентрации напряжений, метод конечных элементов.

UDC 539.3

\author{
E. L. Hart, Dr. Sci. (Phys.-Math.), Y. V. Rybalko
}

\section{INTERACTION OF THE CIRCULAR HOLE AND THE ENVIRONMENT OF ITS ELLIPTIC INCLUSIONS WHEN ELASTIC DEFORMATION OF A RECTANGULAR PLATE}

The stress-strain state of a rectangular elastic plate with one circular hole surrounded by two or four elliptic inclusions is investigated. The influence of the distance between the hole and inclusions, the method of their location and mechanical properties on the stress-strain state of the plate in places of local stress concentrators on the basis of the finite element analysis is studied.

Keywords: rectangular elastic plate, circular hole, elliptic inclusions, stress concentration coefficient, finite element method.

Introduction. The thin-walled structures, elements of which are plates and shells, have been widely used in various fields of technology - aviation, building, shipbuilding, engineering, petroleum industry, and others. Violations of continuity (openings, pores, cracks) and the presence of various inclusions in the material $[1,10]$ are a factor that determines the heterogeneity of the structure and has a substantial influence on the concentration of stress and the processes of deformation and destruction of solids.

The methods of calculation of the plate-shell structures with holes the different external loadings are considered in many publications. We will highlight some of them [2-9, 11-14].

In this paper, the stress-strain state (SSS) of a rectangular plate with one circular holes surrounded by two or four elliptic inclusions from another material is investigated. The finite-element analysis of the influence of the distance between the holes and the inclusions, their number, method of arrangement and mechanical properties on the SSS of the plate in the places of local stress concentrators is carried out. 
Formulation of the problem. A rectangular homogeneous isotropic elastic plate of size $L_{1}, L_{2}$ wits one circular hole of radius $r$ and two or four elliptic inclusions ( $a, b$ - larger and smaller semiaxis of the ellipsis), which are symmetrically located with respect to the hole at a distance $l$ between their centers is given. On the inside boundary of the hole of plate normal and tangential stresses equal to zero, and on the outside boundary of the plate stresses are given.

It is necessary to determinate the SSS of this plate with different distance between hole and inclusions, location method of inclusions and their mechanical properties on the stress-strain state of the plate in the areas of local stress concentrators under the action of the tensile load. A comparative analysis of the obtained results with solutions for the plate without inclusions is carried out.

Conclusions. On the basis of the conducted analysis of the got results it is possible to make conclusion about substantial influence of distance between inclusions and hole, their location, and also about influence of material properties including on SSS of plate at the hole's location.

At a case of vertical location of inclusions : at $k>1$ ( $k$ - the coefficient relative stiffness of inclusion, $k=E_{6 \kappa л} / E_{n л}$, where $E_{6 \kappa л}$ - inclusion elastic modulus; $E_{n л}$ - plate elastic modulus) with reduction a distance $l$ between inclusions and hole there is an increase of the stress concentration coefficient (SCC), here at the least from the considered distances this index increased to $\sim 10 \%$; when $\mathrm{k}<1$ with reduction a distance $l$ value of SCC diminished, and at the least from the considered distances this index diminished to $\sim 19 \%$.

At a case of location of inclusions under the corner of $45^{\circ}$ : at $k>1$ with reduction a distance $l$ value of SCC diminished, a new mechanical effect is here educed: the location of zones of local concentration changed, and at the least from the considered distances $l$ value of SCC diminished on $8 \%$; when $\mathrm{k}<1$ there are an increase of SCC and also mechanical effect : change location of dangerous points.

At a case of horizontal location of inclusions : at $k>1$ with reduction a distance $l$ value of SCC diminished, and at the least distance $l$ value of SCC diminished on $~ 33 \%$; when $k<1$ there is an increase of SCC, here at the least from the considered distances value of SCC increased on $~ 39 \%$.

At a case of symmetric location of four inclusions under the corner of $45^{\circ}$ : at k>1 with reduction to distance $l$ value of SCC diminished, and at the least distance $l$ value of SCC diminished on $\sim 19 \%$; when $\mathrm{k}<1$ there is an increase of SCC, here at the least distance SCC-value increased.

At a case of symmetric location of four inclusions : at $k>1$ with reduction a distance $l$ value of SCC increased to $\sim 3 \%$ but farther with approaching inclusions to hole the value of SCC diminished on $26 \%$; when $k<1$ there is insignificant reduction of SCC to $\sim 8 \%$, when $l=3 r$, but at $l=2.5 r$ value of SCC increased on $\sim 16 \%$. 
So, it is possible to make conclusion from the cases of inclusion's location considered in this work, that for more "hard" inclusions $(k>1)$ the best case is a variant them horizontal location that allowed to decrease the value of SCC on $\sim 33 \%$. For "soft" inclusions $(k<1)$ is a case them vertical location, here the value of SCC decrease on $19 \%$.

A new mechanical effect has been discovered that is associated with the influence of a certain arrangement of elliptical inclusions ("hard" or "soft") around a circular hole on the displacement (shift) of the areas of maximum stress in a given direction. This makes it possible to control the location of stress concentration zones around the hole due to a certain location of inclusions.

\section{REFERENCES}

1. Vanin G. A. Micromechanics of composites. Kiev: Naukova dumka, 1985. 302 p. (in Russian).

2. Washizu K. Variation methods in the theory of elasticity and plasticity. Moscow: Mir, 1987. 544 p. (in Russian).

3. Hart E. L. Finite element analysis of plane-deformable media with inclusions // Bulletin of Dnepropetr. University. Serie: Mechanics. 2011. Vol. 15, iss. 2. P. 39-47. (in Russian).

4. Hart E. L., Panchenko S. V. Numerical analysis of the stress-stain state of a plate with a rectangular hole, supported by triangular overlays // Problems of Computational Mechanics and Strength of Structures: Col. of sci. art. Dnepropetrovsk: Lira, 2015. Vol. 24. P. 35-47. (in Russian).

5. Hart E. L., Nizhnichenko E. A. Numerical analysis of the equilibrium of an elastic plate with inclusion based on the projection-iterative version of the finite element method // Technical Mechanics. 2011. No. 1. P. 61-69. (in Ukrainian).

6. Hart E. L., Hudramovich V. S. Projection-iterative schemes for implementation of the finite element method in problems of deformation of plates with holes and inclusions // Mathem. methods and phys.-mech. fields. 2013. Vol. 56, No. 2. P. 48-59. (in Ukrainian).

7. Hart E. L., Reznik V. A. Computer simulation of the behavior of a plate with two rhomboid holes // Problems of Computational Mechanics and Strength of Structures: Col. of sci. art. Dnipro: Lira, 2017. Vol. 27. P. 43-51. (in Ukrainian).

8. Hudramovich V. S., Hart E. L., Strunin K. A. Computer simulation of the behavior elastic medium with two connected elliptical inclusions // Problems of Computational Mechanics and Strength of Structures: Col. of sci. art. Dnipro: Lira, 2017. Vol. 26. P. 42-50. (in Russian).

9. Savin G. N. Stress distribution around holes. Kiev: Naukova dumka, 1968. 888 p. (in Russian).

10. Shtern M. B., Rud V. D. Mechanical and computer models of consolidation of granulated environments based on powdered metals and ceramics in deformation and sintering / Edited by V. V. Skorohod. Lutsk: Lutsk nat. techn. Univ., 2010. 232 p. (in Ukrainian).

11. Gudramovich V. S., Gart É. L., Strunin K. A. Modeling of the behavior of planedeformable elastic media with elongated elliptic and rectangular inclusions // Materials Science. 2017. Vol. 52, iss. 6. P. 768-774.

12. Hart E. L., Hudramovich V. S. Projection-iterative schemes for the realization of the finite-element method in problems of deformation of plates with holes and inclusions // Journal of Mathematical Sciences. 2014. Vol. 203, No. 1. P. 55-69.

13. Hart E. L., Hudramovich V. S. Projection-iterative modification of the method of local variations for problems with a quadratic functional // J. Appl. Math. Mech. 2016. Vol. 80, iss. 2. P. 156-163.

14. Zienkiewicz O. C., Taylor R. L. The finite element method for solid and structural mechanics. New York: Elsevier, 2005. 632 p.

Дніпровський національний

університет імені Олеся Гончара,

Дніпро, Україна

Надійшла до редколеаії 20.06.2019 